\title{
ELEIÇÕES MUNICIPAIS NO BRASIL: UMA ANÁLISE NA EVOLUÇÃO DO PERFIL SOCIAL E IDEOLÓGICO DOS CANDIDATOS E DOS PREFEITOS ELEITOS EM 20 ANOS (1996 - 2016)
}

\author{
Vinicius Gomes da Silva ${ }^{1}$
}

\section{Resumo}

Este artigo tem como objetivo analisar a evolução do perfil social e ideológico de homens e mulheres nas últimas seis eleições majoritárias municipais realizadas no Brasil. Para tal estudo, serão levantados os dados biográficos dos candidatos, candidatas, eleitos e eleitas nas disputas eleitorais ocorridas em todos os municípios brasileiros nos anos de 1996, 2000, 2004, 2008, 2012 e 2016, analisando as mudanças, estabilidades e diferenças em suas principais características, tais como: sexo, idade, escolaridade e suas ideologias. A principal fonte para a coleta dos dados deste trabalho são as informações disponibilizadas pelo Tribunal Superior Eleitoral. As análises estatísticas descritivas e os cruzamentos dos dados coletados foram processados pelo software de análise de estatística SPSS. Os resultados mostram que existe uma grande diferença entre mulheres e homens participando de eleições majoritárias municipais e um número bem menor delas, sendo eleitas para ocupar o cargo de prefeita. Há uma tendência de aumento na faixa etária dos candidatos e dos prefeitos, tanto das mulheres quanto dos homens, apontando para um "envelhecimento" dos administradores nos executivos municipais. O nível de escolaridade dos candidatos e dos prefeitos é alto e foram os partidos de direita e de centro que mais lançaram candidatos nas últimas seis eleições, pertencendo, também, a partidos desses dois espectros a grande maioria dos prefeitos que foram eleitos.

Palavras - chave: Classe política, Eleições municipais, Prefeitos, Brasil.

\begin{abstract}
This article aims to analyze the evolution of the social and ideological backgrounds of men and women in the last six municipal majority elections held in Brazil. For this study, the biographical data of the candidates, and elected in the electoral disputes that occurred in all Brazilian municipalities in the years 1996, 2000, 2004, 2008, 2012 and 2016 will be collected, analyzing the changes, stabilities and differences in its main characteristics, such as: sex, age, education and its ideologies. The main of the data of this work is information made available by the Superior Electoral Court. The descriptive statistical analyzes and the crossings of the collected data were processed by the statistical analysis software SPSS. The results show that there is a great difference between women and men participating in municipal majority elections and a much smaller number of them being elected to occupy the position of mayor. There is a trend towards an increase in the average age of candidates and mayors, both women and men, pointing to an "aging" of the managers of municipal executives. The education level of candidates and mayors is high and it was the right and center parties that most launched candidates in the last six elections, the majority of the mayors who were elected also belonging to parties of these two specters.
\end{abstract}

Keywords: Political class, Municipal elections, Mayors, Brazil.

\footnotetext{
${ }^{1}$ Bacharel em Administração Pública - LGPP/UENF. E-mail: gomesvinny@yahoo.com.br
} 


\section{Resumen}

Este artículo tiene como objetivo analizar la evolución del perfil social e ideológico de hombres y mujeres en las últimas seis elecciones municipales mayoritarias celebradas en Brasil. Para este estudio se recogerán los datos biográficos de los candidatos y electos en las disputas electorales ocurridas en todos los municipios brasileños en los años 1996, 2000, 2004, 2008, 2012 y 2016, analizando los cambios, estabilidades y diferencias en sus principales características, tales como: sexo, edad, educación y sus ideologías. La principal fuente para la recolección de los datos de este trabajo es la información puesta a disposición por el Tribunal Superior Electoral. Los análisis estadísticos descriptivos y los cruces de los datos recolectados fueron procesados por el software de análisis estadístico SPSS. Los resultados muestran que hay una gran diferencia entre mujeres y hombres que participan en las elecciones ejecutivas municipales y un número mucho menor de ellas son elegidos para ocupar el cargo de alcalde. Existe una tendencia al aumento de la edad promedio de los candidatos y alcaldes, tanto mujeres como hombres, lo que apunta a un "envejecimiento" de los gerentes de los ejecutivos municipales. El nivel de educación de los candidatos y alcaldes es alto y fueron los partidos de derecha y centro los que más lanzaron candidatos en las últimas seis elecciones, la mayoría de los alcaldes electos también pertenecían a partidos de estos dos espectros.

Palabras clave: Clase política, Elecciones municipales, Alcaldes, Brasil.

\section{INTRODUÇÃO}

O estudo da classe política vem adquirindo grande importância, pois nas democracias modernas são os representantes desse grupo que controlam o processo decisório, impactando ou não as sociedades de uma forma geral. Tais estudos buscam pesquisar com o intuito de conhecer a composição social e política daqueles que são recrutados pelos partidos políticos, analisando o processo de formação desses representantes, as suas carreiras, experiências, trajetórias políticas, os partidos aos quais foram filiados e eleitos, o tempo de dedicação à vida política, dentre outras variáveis. Contudo, a maior parte dos trabalhos sobre esse tema tem dado mais ênfase aos cargos de deputados federais ${ }^{2}$ e senadores ${ }^{3}$. No Brasil, ainda, observa-se que há uma tendência a concentrar as análises no perfil social apenas naqueles que "chegaram lá", isto é, nos ocupantes dos postos mais importantes do sistema político brasileiro, deixando de fora, muitas vezes, aqueles que estão tentando "chegar lá” (PERISSINOTTO; BOLOGNESI, 2009, p. 114).

Este trabalho tem o objetivo de identificar as principais mudanças ou estabilidades nas características do perfil social e ideológico de um dos coletivos que tem sido pouco estudado ${ }^{4}$ : os candidatos nas eleições majoritárias municipais e os prefeitos dos municípios brasileiros nos últimos 20 anos. Para tanto, foram levantados os dados biográficos dos candidatos e dos prefeitos eleitos nas disputas eleitorais ocorridas em todos os municípios brasileiros, nos anos de 1996,

\footnotetext{
${ }^{2}$ Braga, Veiga e Miríade (2009), Perissinotto e Bolognesi (2010), Perissinotto e Miríade (2009), Rodrigues (2002), (2006), Santos (2010), Silva Júnior e Figueiredo Filho (2012).

${ }^{3}$ Araújo (2011), Costa (2010), Costa e Codato (2013), Lemos e Ranincheski (2003), Neiva e Izumi(2012), Silva (2010).

${ }^{4}$ Alcántara (2016), Codato, Cervi e Perissinotto (2013).
} 
2000, 2004, 2008, 2012 e 2016, analisando as mudanças, estabilidades e diferenças em suas principais características, como: sexo, idade, escolaridade e, ainda, as ideologias partidárias dos candidatos nas eleições majoritárias municipais e dos prefeitos. A escolha dessas variáveis permite, também, a comparação com estudos de outros cargos eletivos e que utilizam a mesma base de dados do TSE. Além de uma análise mais geral sobre o perfil dos candidatos e dos prefeitos ao longo do período indicado, será feita uma comparação da evolução no tempo de cada variável.

Estudar o perfil da classe política recrutada pelo sistema partidário é importante para se compreender quem são os indivíduos que estão à disposição para o eleitorado (SILVA; SILVA, 2015, p. 341). Já conhecer o perfil dos chefes dos executivos municipais torna-se interessante, quando, através da promulgação da Constituição Federal de 1988, os municípios ganharam importante papel na gestão local brasileira, trazendo para esses entes federativos autonomias e muitos incrementos nas competências municipais. Todo esse protagonismo cria vários desafios para o chefe da administração municipal, que passa a encontrar novos ambientes com os quais precisa lidar e entregar respostas minimamente adequadas à sociedade.

A primeira disputa eleitoral selecionada deste trabalho corresponde à eleição municipal de 1996. Tal recorte se justifica pela possibilidade de uma reeleição nos pleitos municipais subsequentes $^{5}$ a essa eleição. A comparação com os candidatos e prefeitos das eleições recentes, permitirá analisar a evolução no perfil dos mesmos ao longo de 20 anos, nos quais houve alternâncias políticas no governo e mudanças sociais e econômicas muito relevantes.

Para melhor compreensão, este trabalho está dividido em três partes: A primeira trará algumas observações metodológicas utilizadas na pesquisa. A segunda apresentará os perfis dos candidatos nas eleições majoritárias municipais e dos prefeitos eleitos nos últimos 20 anos, como: sexo, idade, escolaridade e suas ideologias. E a terceira apresentará as considerações finais desta pesquisa.

\section{OBSERVAÇÕES METODOLÓGICAS}

A principal fonte desta pesquisa é uma base de dados elaborada com informações disponíveis para todos os candidatos das eleições majoritárias municipais e os eleitos nos pleitos de outubro de 1996, 2000, 2004, 2008, 2012 e 2016, editadas no ato de registro das candidaturas, sendo elas autodeclaradas, ou seja, os dados se baseiam em informações que os próprios candidatos fornecem aos tribunais regionais eleitorais, nos estados, e ao Tribunal Superior Eleitoral (TSE). Essas informações identificam a situação do candidato no momento de cada

\footnotetext{
${ }^{5}$ Emenda Constitucional No 16, de 04 de junho de 1997.
} 
eleição e estão disponíveis nos sites dos tribunais regionais eleitorais nos estados e no Repositório de Dados Eleitorais do TSE. Como fontes complementares, foram utilizadas as informações das biografias dos pesquisados disponíveis em páginas pessoais, institucionais e dos respectivos partidos políticos, assim como informações disponíveis na base de dados "Políticos do Brasill, do site Poder 360, sob a direção de redação de Fernando Rodrigues, e do Dicionário Histórico-Biográfico Brasileiro (DHBB), elaborado pelo Centro de Pesquisa e Documentação Contemporânea do Brasil (CPDOC) da Fundação Getúlio Vargas (FGV).

A base de dados é composta por quase 96 mil candidatos de seis eleições majoritárias municipais, com uma média de, aproximadamente, 16 mil candidatos por eleição. A análise abrange todos os municípios brasileiros e estende-se por duas décadas de competição eleitoral municipal, de 1996 a 2016.

A unidade de análise será composta por todos os candidatos nas eleições majoritárias municipais, independente do fato de terem seu registro deferido ou não e seus prefeitos eleitos. No entanto, só serão considerados aqueles efetivamente eleitos para o cargo, independentemente de terem continuado ou não no mandato por todo o período para o qual foram eleitos. Não serão considerados nessa análise aqueles que em algum momento ocupou temporariamente o cargo ou que assumiu efetivamente o mandato devido à perda, afastamento, cassação ou morte do titular do mandato. Os resultados eleitorais foram retirados do site do TSE.

Serão utilizadas quatro variáveis para se investigar o perfil dos candidatos e dos prefeitos: sexo, idade, escolaridade e a ideologia. As análises estatísticas descritivas e os cruzamentos dos dados coletados foram processados pelo software de análise de estatística SPSS. Vale destacar que, na eleição de 1996, alguns dados estão incompletos em alguns estados, pois nessa eleição o sistema eleitoral não era eletrônico. A falta dessas informações se reflete nos resultados, mas não inviabiliza a análise.

Para melhor compreensão, no nível de escolaridade a variável "até Ensino Fundamental" agregou-se a todos aqueles que declararam "ler e escrever", e aqueles com "Ensino Fundamental Incompleto", com "Ensino Fundamental Completo" e com "Ensino Médio Incompleto". A variável "Ensino Médio" contém aqueles que declararam possuir "Ensino Médio Completo" e "Ensino Superior Incompleto".

Por fim, a classificação ideológica dos partidos seguiu a distribuição usual na literatura ${ }^{6}$. Foram considerados partidos de "esquerda" o PCB, PCdoB, PCO, PDT, PGT, PMN, PPL, PPS, PSB, PSOL, PROS, PST, PSTU, PT, PV e REDE; de “centro", ficaram PMB, PMDB, PSD e

\footnotetext{
${ }^{6}$ Miguel (2004), Marenco e Serna (2007).
} 
PSDB; e, de “direita”, DEM (ex-PFL), NOVO, PAN, PEN, PHS, PP (x-PPB), PR (ex-PL), PRB, PRONA, PRP, PRTB,PSC, PSDC, PSL, PT do B, PTB, PTC, PTN e SD.

\section{PERFIL SOCIAL: SEXO, IDADE, ESCOLARIDADE E ESPECTRO IDEOLÓGICO DOS CANDIDATOS E DOS PREFEITOS BRASILEIROS (1996 - 2016)}

Esta seção tem por objetivo analisar o perfil social e ideológico dos candidatos e dos prefeitos brasileiros das últimas duas décadas, determinando alguns padrões sociais que facilitariam o acesso à seleção dos candidatos para se obter um maior êxito eleitoral e, ainda, mostrando as diferenças dessa classe com relação ao conjunto da população. Cabe destacar que, para o desenvolvimento desta seção, as análises terão caráter mais descritivo, possuindo como base o banco de dados já mencionado na metodologia deste trabalho.

A primeira variável a ser analisada diz respeito ao sexo dos candidatos nas eleições majoritárias municipais e dos prefeitos. É perceptível que praticamente em todas as sociedades, as atividades políticas vêm sendo desempenhadas essencialmente por homens, existindo uma baixa representação das mulheres, tanto nas casas legislativas quanto nas cadeiras executivas.

Uma das explicações para esse fato é que os homens são socializados para ver a política como uma área de atuação legítima, ao contrário das mulheres, o que os leva a desenvolver um maior interesse pela área da política, e, consequentemente, a ter mais ambição política do que elas (MIGUEL; MARQUES; MACHADO, 2015, p. 735). Às mulheres, então, caberia transpassar o preconceito que é disseminado nessas sociedades, fazendo com que elas sejam vistas como estando deslocadas no campo político, fora de seu meio "natural", e, portanto, tenham menos chances de serem votadas (MIGUEL; QUEIROZ, 2006, p. 365).

O pequeno espaço ocupado pelas mulheres nas disputas eleitorais, também, pode ser explicado pela falta de paridade dentro das estruturas dos partidos políticos e um menor número delas na lista de filiados (FRASER; HONNETH, 2003; PINTO; SILVEIRA, 2018, p. 179-180). Os homens também seriam privilegiados logo no processo de seleção dos aspirantes a ocupar cargos eletivos. Nessa primeira etapa do recrutamento político, há, sempre, mais homens que mulheres, pois o ambiente partidário e de recrutamento, normalmente, é mais favorável para eles, ou seja, a desigualdade na participação é notória no primeiro passo do recrutamento dos possíveis políticos.

Os homens, ainda, seriam privilegiados na mobilização dos recursos partidários. Nesse caso, a legislação seria omissa quanto à distribuição dos recursos de campanha, que permanecem, em grande medida, monopolizados pelos candidatos homens, que são maioria na composição das direções partidárias (MATLAND, 2005; MIGUEL; QUEIROZ, 2006, p. 366; MIGUEL; 
MARQUES; MACHADO, 2015, p.735). Apenas recentemente, com a Resolução no 23.553/2017, de 15 de março de 2018, o TSE definiu que os partidos devem obrigatoriamente repassar 30\% dos recursos públicos de campanhas para as mulheres. Para elas, devem ser destinadas, ainda, o limite de 30\% do tempo de propaganda eleitoral no rádio e na televisão.

Outros pesquisadores apontam que o baixo número de candidatas e de eleitas deve-se ao fato do número extremamente baixo de mulheres que ocupam posições de alto nível nas profissões que servem como condutor para carreiras na política (DARCY; WELCH; CLARK, 1994; CONWAY; STEURNAGLE; AHERN, 1997; DUERST-LAHTI, 1998; THOMAS, 1998). À medida que a presença das mulheres nos campos do direito e dos negócios se tornar mais comparável ao dos homens, o mesmo acontecerá com seu status econômico e sua probabilidade de concorrer a cargos eletivos (CLARK, 1994; DARCY; WELCH; CLARK, 1994).

Mesmo as mulheres sendo maioria entre os eleitores brasileiros desde a eleição de 2000, esse poder majoritário de voto não chegou a transformar a representação por gênero nas instâncias de poder, pois diversos estudos, em âmbito nacional e internacional, apresentam a baixa participação e representação de mulheres em todos os cargos eletivos. $\mathrm{Na}$ análise das eleições para o cargo executivo municipal, não foi diferente. Verifica-se, pela análise do Gráfico 1, a grande diferença entre mulheres e homens participando das eleições e um número bem menor delas sendo eleitas para ocupar o cargo de prefeita nos últimos 20 anos.

Gráfico 1 - Sexo dos candidatos nas eleições majoritárias municipais e dos prefeitos (1996-2016)

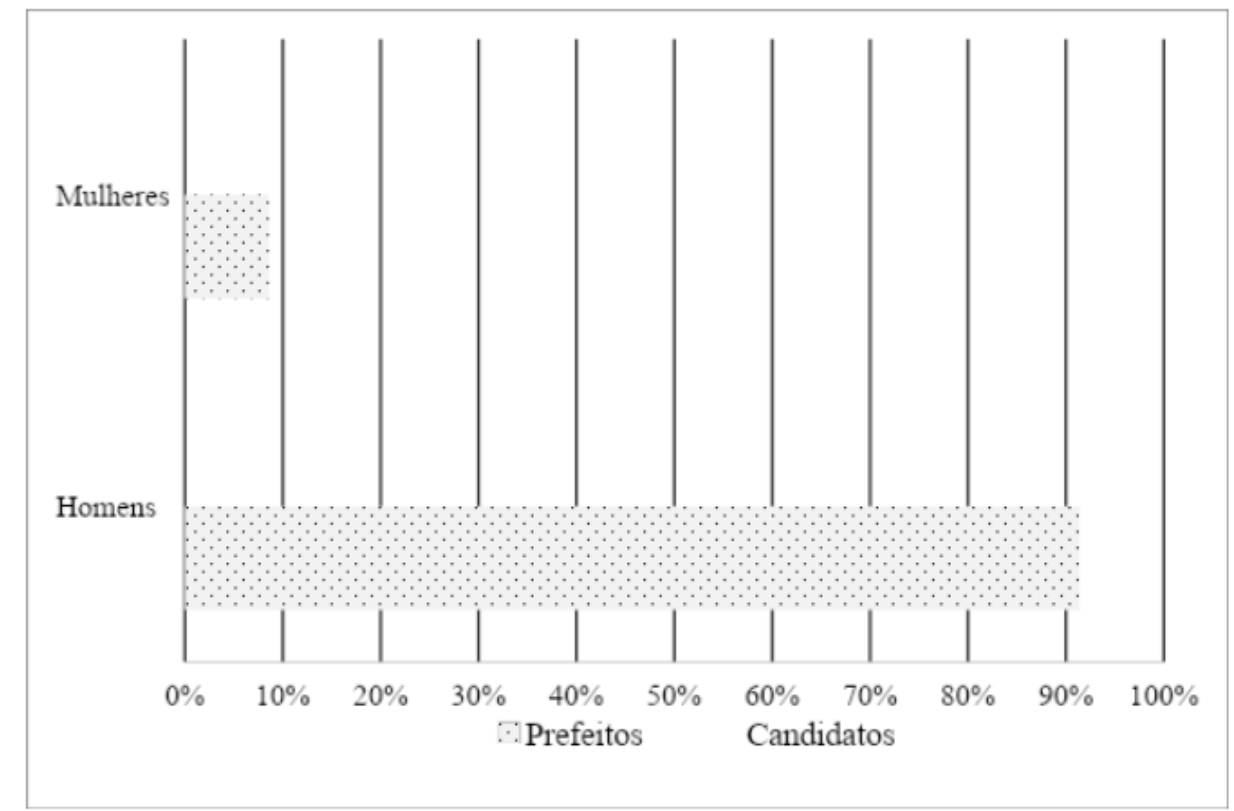

Fonte: Elaboração do autor com dados do Tribunal Superior Eleitoral (2020) 
$\mathrm{Na}$ evolução do tempo, o percentual de homens que são selecionados para disputar um cargo majoritário municipal teve uma queda. Já as mulheres, apesar dos números ainda serem baixos, o percentual de candidatas aumentou, aproximadamente, 78 p.p. (Tabela 1). Na análise do sexo dos prefeitos (Tabela 2), os resultados também mostram que ocorreu uma redução no percentual de homens e um crescimento de 127,4 p.p. de mulheres ocupando o cargo de prefeita (saindo de 5,1\%, em 1996, para 11,6\%, em 2016).

Esses resultados apontam que não há grandes diferenças entre os percentuais de mulheres que são eleitas para o executivo municipal em comparação com outros estudos sobre mulheres em eleições majoritárias ${ }^{7}$ e proporcionais $^{8}$. O único cargo eletivo que diverge com índices superiores aos encontrados nesta pesquisa são de mulheres brasileiras na disputa para o legislativo municipal, conforme encontrado em Alves, Cavenaghi e Alcântara (2007) e em Bohn (2009).

Tabela 1 - Evolução no sexo dos candidatos nas eleições majoritárias municipais (em \%)

\begin{tabular}{lcccccc}
\hline & 1996 & 2000 & 2004 & 2008 & 2012 & 2016 \\
\hline Mulheres & 7,3 & 7,6 & 9,5 & 11,1 & 13,3 & 13 \\
Homens & 92,2 & 92,4 & 90,5 & 88,9 & 86,7 & 87 \\
\multirow{2}{*}{ Sem dados } & 0,5 & 0 & 0 & 0 & 0 & 0 \\
\multirow{2}{*}{$\mathrm{N}$} & 100 & 100 & 100 & 100 & 100 & 100 \\
& $(15359)$ & $(15155)$ & $(16127)$ & $(16139)$ & $(16201)$ & $(16879)$ \\
\hline
\end{tabular}

Fonte: Elaboração do autor com dados do Tribunal Superior Eleitoral (2020).

Os dados permitem inferir que, com o aumento no número de candidatas nas disputas, há um aumento no número de mulheres eleitas. Na comparação, 2012 é o período com maior crescimento de mulheres disputando e vencendo um cargo majoritário municipal, tendo como possível explicação a vitória da presidenta Dilma Rousseff - PT - no pleito presidencial de 2010, mas existe um pequeno declínio no número de candidatas e de prefeitas na eleição municipal de 2016, período em que o Brasil passava por uma forte crise política e econômica, causando o impeachment da presidenta Dilma Rousseff, possivelmente, afetando o número de candidaturas e a eleição de mulheres.

\footnotetext{
${ }^{7}$ Ver Massia (2013).

${ }^{8}$ Ver Costa (2010) e Pratti (2013).
} 
Tabela 2 - Evolução no sexo dos prefeitos (em \%)

\begin{tabular}{lcccccc}
\hline & 1996 & 2000 & 2004 & 2008 & 2012 & 2016 \\
\hline Mulheres & 5,1 & 5,8 & 7,4 & 9,4 & 11,9 & 11,6 \\
Homens & 94,6 & 94,2 & 92,6 & 90,6 & 88,1 & 88,4 \\
\multirow{2}{*}{ Sem dados } & 0,3 & 0 & 0 & 0 & 0 & 0 \\
$\mathrm{~N}$ & 100 & 100 & 100 & 100 & 100 & 100 \\
& $(5408)$ & $(5584)$ & $(5521)$ & $(5694)$ & $(5673)$ & $(5615)$ \\
\hline
\end{tabular}

Fonte: Elaboração do autor com dados do Tribunal Superior Eleitoral (2020).

Vale ressaltar que, em disputas eleitorais para cargos executivos, não há a utilização da legislação de cotas (Lei no 9.504/1997, Lei 12.034/2009, Lei no 13.165/2015) ao partido político e/ou à coligação. Só é permitido lançar um único candidato para disputar o cargo de prefeito. Então, o aumento no número de mulheres disputando o cargo executivo municipal (Tabela 1) não tem ligação com a legislação de cotas, mas pode ser uma consequência desse sistema de reserva de vagas, pois uma vez a mulher tendo mais espaço para disputar e vencer eleições para cargos nos legislativos, é possível aumentar a ambição política nas mulheres e/ou cacifá-las para disputar cargos majoritários (prefeitos, governadores, senadores e etc.). Cabe registrar ainda que, nos últimos anos, o Tribunal Superior Eleitoral e várias outras instituições vêm constantemente promovendo, incentivando e desenvolvendo várias campanhas e programas para a inserção e participação das mulheres na vida política e nas disputas eleitorais.

A taxa de sucesso das mulheres tem aumentado consideravelmente nas disputas pelos governos municipais e a força eleitoral dos homens, que se mostra superior às mulheres, vem caindo gradualmente (Gráfico 2): a diferença que já foi de 11,5 p., em 1996, diminuiu para 4,2 p., em 2016. Essa superioridade da taxa de sucesso dos homens sobre as mulheres é encontrada no estudo sobre o poder executivo estadual brasileiro, onde Massia (2013, p. 88) encontrou um aproveitamento de 11,6\% para os candidatos que se elegeram governadores entre 1994 e 2010 e 10,6\% para as candidatas. Um cenário divergente é o estudo de Bohn (2008) sobre os candidatos e candidatas ao Senado Federal no período de 1994 a 2002, tendo as candidatas ao Senado obtido um desempenho melhor que os candidatos em disputas pelas cadeiras vagas (11,0\% contra 7,9\%, respectivamente). 

prefeitos eleitos em 20 anos (1996-2016). DOI: http://dx.doi.org/10.5380/recp.v11i1.74615

Gráfico 2 - Índice de sucesso de mulheres e homens nas eleições majoritárias municipais (em \%)

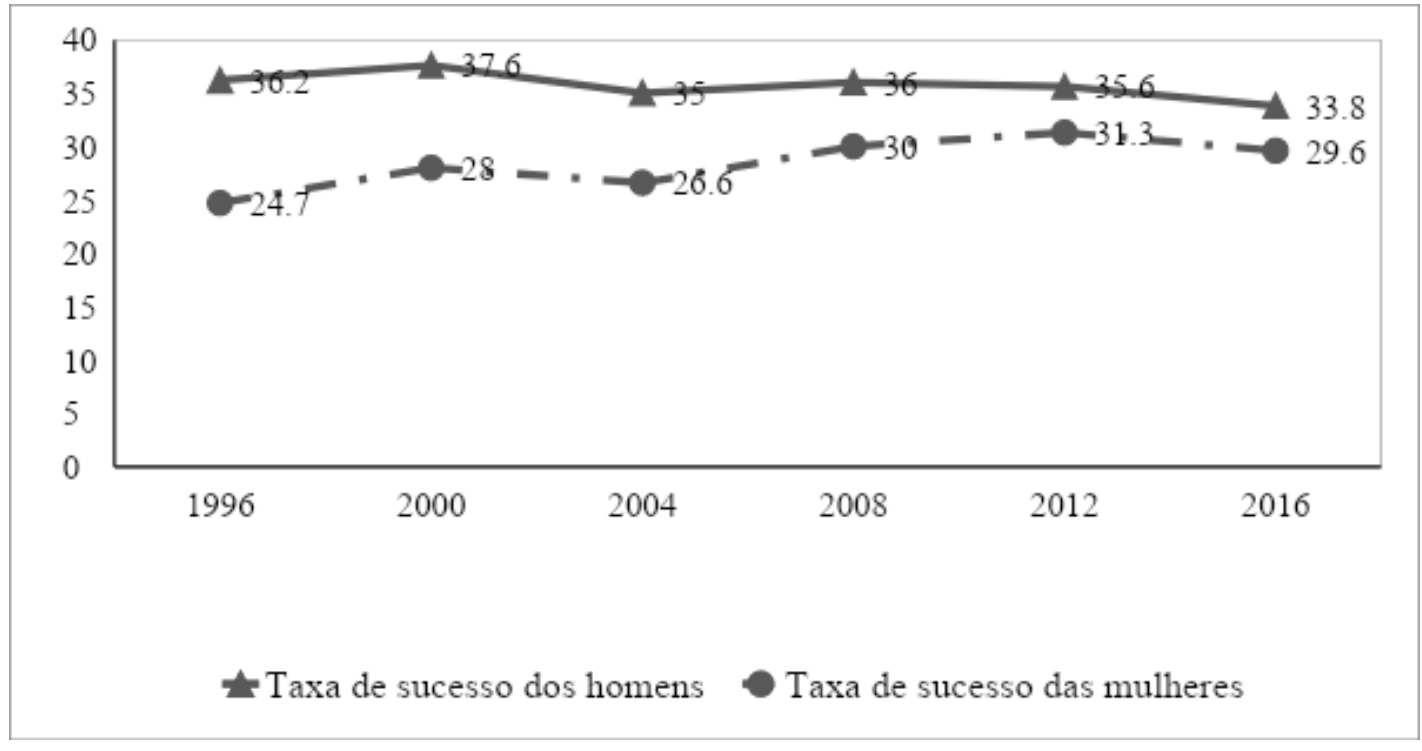

Fonte: Elaboração do autor com dados do Tribunal Superior Eleitoral (2020).

A segunda variável a ser analisada é a idade dos candidatos e dos prefeitos. Apesar da idade mínima estabelecida na Constituição Federal de 1988 para ocupar o cargo de prefeito municipal ser de 21 anos, a média de idade dos candidatos e dos prefeitos é bem superior a esse patamar mínimo, conforme pode ser visto nas Tabelas 3, 4 e 5, mas a média de idade das prefeitas e dos prefeitos tende a ser menor que a média de idade das candidatas e dos candidatos nas eleições majoritárias municipais. A idade das mulheres fica em torno de 46 anos para as candidatas e prefeitas, abaixo da idade dos homens, que é de 48 anos para os candidatos e 47 anos para os prefeitos. Nessa análise, esperava-se que as mulheres tivessem uma idade superior a dos homens, devido aos fatores que retardam a entrada delas na atividade política, hipótese essa que não aconteceu.

Tabela 3 - Média de idade dos candidatos nas eleições majoritárias municipais e dos prefeitos $(1996-2016)$

\begin{tabular}{lcccc}
\hline & \multicolumn{2}{c}{ Candidatos } & \multicolumn{2}{c}{ Prefeitos } \\
\hline \multirow{2}{*}{ Média } & Mulheres & Homens & Mulheres & Homens \\
D. S. & 46,5 & 48,3 & 46,6 & 47,9 \\
\hline
\end{tabular}

Fonte: Elaboração do autor com dados do Tribunal Superior Eleitoral (2020). 
$\mathrm{Na}$ evolução do tempo, nota-se uma tendência no aumento da média das idades, tanto das mulheres como dos homens, apontando para um "envelhecimento" dos administradores que comandam os executivos municipais. Enquanto, na eleição de 1996, foram eleitos candidatos com a menor média de idades, configurando como o pleito em que se elegeu prefeitas e prefeitos com uma maior média de idade no período, aumentando a idade média das prefeitas em 2 anos (passando de 45 anos para 47 anos), entre os homens o aumento foi de 4 anos (saindo de 45 anos em 1996 para 49 anos em 2016). Essa tendência no envelhecimento dos políticos brasileiros encontra-se em outros estudos ${ }^{9}$ e pode ser o efeito do fim das restrições às atividades políticas, já que, antes da década de 1990, as disputas eleitorais eram restritas a poucos competidores ou pode ser explicada por uma, possível, preferência do eleitorado por uma classe política com mais experiência ou com mais maturidade.

Os dados mostram ainda que, apesar do aumento progressivo nas idades das candidatas e dos candidatos, apenas na eleição de 2004, primeira eleição municipal após a vitória do Partido dos Trabalhadores para a presidência da república, em 2002, há uma redução relativa na média de idades das prefeitas e nos prefeitos eleitos, podendo ser associada a uma renovação na classe política dos executivos municipais, junto com a renovação da classe política no Governo Federal e no Congresso ${ }^{10}$.

Tabela 4 - Evolução na média de idade das mulheres nas eleições majoritárias municipais

\begin{tabular}{lcccccc}
\hline & 1996 & 2000 & 2004 & 2008 & 2012 & 2016 \\
\hline Candidatas & 42,7 & 45,7 & 46,0 & 46,8 & 47,0 & 47,9 \\
D. S. & 9,9 & 9,3 & 9,0 & 9,1 & 9,8 & 10,3 \\
Prefeitas & 45,4 & 46,5 & 45,7 & 46,5 & 46,6 & 47,6 \\
D. S. & 9,6 & 8,7 & 9,0 & 9,0 & 9,7 & 10,3 \\
\hline
\end{tabular}

Fonte: Elaboração do autor com dados do Tribunal Superior Eleitoral (2020).

\footnotetext{
${ }^{9}$ Ver Massia (2013) para governadores; Pratti (2013) para deputados estaduais e Silva (2016) para deputados federais do PT, PMDB e PSDB.

${ }^{10}$ Rodrigues (2006).
} 
Tabela 5 - Evolução na média de idade dos homens nas eleições majoritárias municipais

\begin{tabular}{lcccccc}
\hline & 1996 & 2000 & 2004 & 2008 & 2012 & 2016 \\
\hline Candidatos & 46,0 & 48,0 & 48,1 & 48,8 & 48,8 & 49,5 \\
D. S. & 10,2 & 10,0 & 10,1 & 10,3 & 10,5 & 10,9 \\
Prefeitos & 45,9 & 47,8 & 47,6 & 48,1 & 48,2 & 49,2 \\
D. S. & 9,7 & 9,5 & 9,7 & 9,6 & 10,2 & 10,7 \\
\hline
\end{tabular}

Fonte: Elaboração do autor com dados do Tribunal Superior Eleitoral (2020).

A próxima característica a ser analisada dos candidatos nas eleições majoritárias municipais e dos prefeitos será o nível de escolaridade, pois as competências dos prefeitos inseridas na Constituição Federal de 1988 e nas leis orgânicas dos municípios, requerem desses administradores um mínimo de capacitação, conhecimentos ou especialização técnica. A legislação brasileira $^{11}$ veta apenas os analfabetos do exercício da capacidade eleitoral passiva, tornando-os inelegíveis, ou seja, apesar de poderem exercer o direito de voto, os analfabetos não podem ser votados (ALMEIDA, 2019, p. 102). Dessa forma, a alfabetização é um dos pré-requisitos para se entrar em disputas eleitorais no Brasil.

A educação é uma das variáveis apontadas pela literatura como essenciais para o desenvolvimento da ambição política (SOULE, 1969). Cada vez mais se verifica que, quanto maior o volume de capital escolar possuído, maior é a probabilidade de ascensão na carreira política e aqueles que não chegam ao nível superior de escolaridade, têm raras chances de êxito no mercado eleitoral (FREIRE, 1998; PINTO; SILVEIRA, 2018, p. 190). O diploma universitário, além de conferir grande autoridade moral e prestígio social, pode servir como carta de apresentação para um cargo ao maquiar um currículo que pode ser insuficiente para as exigências da nova tarefa (ALCÂNTARA, 2016, p. 197; NORRIS; LOVENDUSKI, 1995). Deve-se, ainda, considerar que o espaço universitário tem sido local de iniciação para muitas carreiras políticas (LODOLA, 2017, p. 97; SIGAL, 2002).

A formação universitária da classe política, pelo menos no âmbito legislativo, registrou um enorme desenvolvimento nas últimas décadas. Atualmente, quase a metade dos países latino-americanos têm mais de $80 \%$ dos seus deputados com uma formação universitária (ALCÂNTARA, 2016, p. 194). Para o caso brasileiro, Massia (2013, p. 102) mostra que 88\% dos governadores eleitos entre 1994 a 2010 possuíam ensino superior. Neiva e Izumi (2012, p. 180) observam o alto nível educacional dos senadores no Brasil no período de 1987 a 2007; apenas $11,3 \%$ dos senadores eleitos durante esse intervalo de tempo não possuíam curso superior

\footnotetext{
${ }^{11}$ Constituição Federal de 1988, art. 14, \ $4^{\circ}$ e Lei Complementar n 64/90, art. 1º, inc. I, "a".
} 
completo. Já Santana (2008, p. 137) destaca que é considerável a taxa dos parlamentares brasileiros que possuíam curso superior com uma pós-graduação ${ }^{12}$, chegando a uma percentagem de $14 \%$.

O nível de escolaridade dos candidatos e dos prefeitos eleitos entre 1996 e 2016 é alto (Gráfico 3), com mais de 42,5\% dos candidatos e dos prefeitos possuindo o ensino superior como grau de instrução. Na evolução do tempo, há ainda um aumento desse tipo de escolaridade, chegando-se ao nível da eleição de 2016 ter mais de 52\% dos candidatos e dos prefeitos eleitos com uma graduação (Tabelas 6 e 7). Na comparação com estudos sobre outros cargos eletivos ${ }^{13}$, as taxas para os candidatos e prefeitos com nível superior são mais baixas, mas são mais altas que o percentual de 19,4\% para os candidatos a vereadores em 2016 encontrado por Peixoto e Silva (2017), mostrando que, quanto mais se avança na hierarquia da classe política, maior é o nível de escolaridade que possuem os políticos, possivelmente por pertencerem às classes mais altas e/ou superiores da sociedade.

Gráfico 3 - Nível de escolaridade dos candidatos nas eleições majoritárias municipais e prefeitos $(1996-2016)$

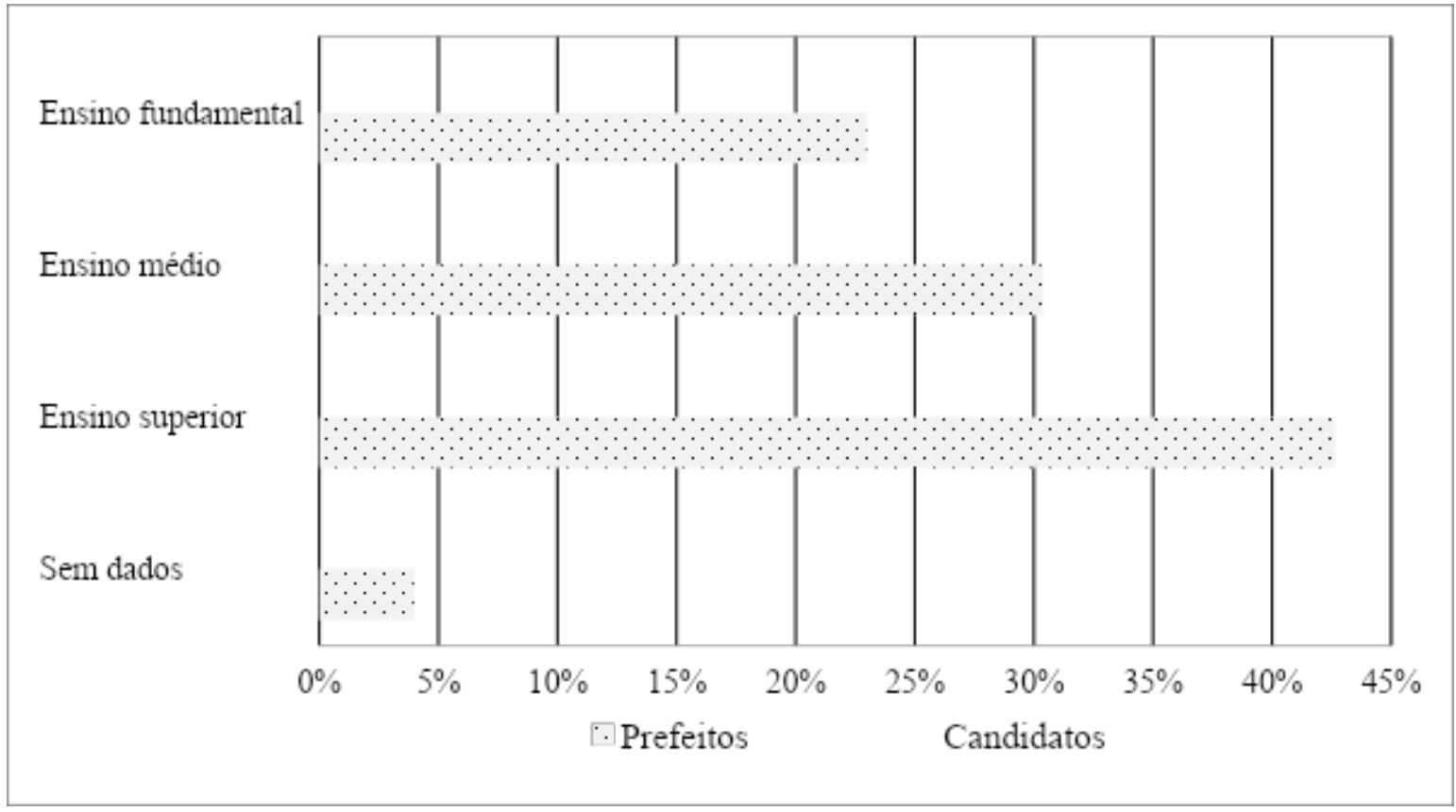

Fonte: Elaboração do autor com dados do Tribunal Superior Eleitoral (2020).

\footnotetext{
${ }^{12}$ Especialização, mestrado ou doutorado.

${ }^{13}$ Costa (2010), Massia (2013), Pratti (2013) e Silva (2016).
} 
Como a maior parte dos municípios brasileiros são pequenos em densidade populacional e se concentram na zona rural ${ }^{14}$, o número de candidatos e de prefeitos com Ensino Fundamental e Médio é grande. Apesar do percentual daqueles que não possuem dados em 1996 ser alto, percebe-se uma redução expressiva na evolução do tempo, nos candidatos e nos prefeitos com Ensino Fundamental: Entre os candidatos, há uma diminuição de 44,9 p. p. no período de 2000 a 2016 (passando de 29,2\% para 16,1\%); já entre os prefeitos, ocorre uma redução ainda maior, de 46,5 p. p. no mesmo período (caindo de 30,3\% para 16,2\%). O percentual daqueles que possuem Ensino Médio também é alto, mas não há grandes variações no período.

Esses dados sobre o nível educacional da classe política e dos prefeitos brasileiros são bem superiores quando comparados ao nível educacional da população, refletindo a valorização social dada à alta escolaridade. Segundo o IBGE ${ }^{15}$, em 2000, apenas 6,8\% dos brasileiros possuíam Ensino Superior, entre a população de 25 anos ou mais idade; já em 2010, esse percentual aumentou para $11,3 \%$. Nesse mesmo período, houve um aumento na população com Ensino Médio, saindo de $16,4 \%$ para 24,6\%. Considerando o sexo da pessoa, o IBGE mostra que em ambos os censos demográficos há mais mulheres que homens com Ensino Superior e Médio. Em 2000 , havia $7 \%$ de mulheres graduadas contra $6,5 \%$ de homens e $17,1 \%$ de mulheres com Ensino Médio contra 15,6\% de homens. No ano de 2010, o percentual de mulheres com Ensino Superior cresceu para 12,5\% e dos homens para 9,9\% e o percentual de mulheres com nível médio passou para $25 \%$ contra $24,1 \%$ de homens.

Tabela 6 - Evolução no nível de escolaridade dos candidatos nas eleições majoritárias municipais $(\mathrm{em} \%)$

\begin{tabular}{lcccccc}
\hline & 1996 & 2000 & 2004 & 2008 & 2012 & 2016 \\
\hline Até o ensino fundamental & 26,6 & 29,2 & 25,3 & 22,3 & 17,5 & 16,1 \\
Ensino Médio & 20,0 & 29,6 & 31,9 & 33,4 & 33,4 & 31,8 \\
Ensino Superior & 27,2 & 40,2 & 42,4 & 44,3 & 49 & 52,2 \\
Sem dados & 26,2 & 1,0 & 0,4 & 0 & 0 & 0 \\
$\mathrm{~N}$ & 100 & 100 & 100 & 100 & 100 & 100 \\
& 15275 & 15155 & 16127 & 16140 & 16202 & 16880 \\
\hline
\end{tabular}

Fonte: Elaboração do autor com dados do Tribunal Superior Eleitoral (2020).

\footnotetext{
${ }^{14}$ Segundo o IBGE, em 1996 no Brasil, 89\% dos municípios tinham população abaixo de 50 mil habitantes; 78\% dos habitantes residiam na zona urbana e $22 \%$ moravam na zona rural. Hoje, cerca de, $90 \%$ dos municípios possuem população inferior a 50 mil habitantes, sendo $60 \%$ deles predominantemente rurais e $26 \%$ são considerados predominantemente urbanos. $\mathrm{Na}$ zona rural, se concentram cerca de $17 \%$ da população, já na área urbana vivem, aproximadamente, $76 \%$ dos brasileiros.

${ }^{15}$ Com base no Censo Demográfico de 2000 e 2010.
} 
Tabela 7 - Evolução no nível de escolaridade dos prefeitos (em \%)

\begin{tabular}{lcccccc}
\hline & 1996 & 2000 & 2004 & 2008 & 2012 & 2016 \\
\hline Até o Ensino Fundamental & 27,8 & 30,3 & 25,2 & 21,8 & 17,1 & 16,2 \\
Ensino Médio & 20,1 & 30,2 & 33,2 & 33,7 & 33,4 & 31,1 \\
Ensino Superior & 28,7 & 38,6 & 41,3 & 44,5 & 49,4 & 52,7 \\
Sem dados & 23,4 & 0,9 & 0,3 & 0 & 0 & 0 \\
\multirow{2}{*}{$\mathrm{N}$} & 100 & 100 & 100 & 100 & 100 & 100 \\
& 5408 & 5585 & 5521 & $5694)$ & 5674 & 5615 \\
\hline
\end{tabular}

Fonte: Elaboração do autor com dados do Tribunal Superior Eleitoral (2020).

Essa tendência de mulheres com maior nível de escolaridade que os homens se reflete claramente nos candidatos e nos prefeitos, quando é analisado o nível educacional por sexo (Tabelas 8, 9, 10 e 11). Os resultados mostram que há um crescimento considerável de mulheres e homens que se candidatam em eleições majoritárias municipais com Ensino Superior, mas tal crescimento é maior entre as mulheres. Enquanto entre os homens, no período de 2000 a 2016, há um crescimento de aproximadamente 25 p. p. de candidatos com Ensino Superior (saindo de $39,4 \%$ para $49,2 \%$ ), entre as mulheres ocorre um aumento de 47 p. p. de candidatas com uma graduação (passando de 49,2\% para 72,2\%). No mesmo período, há um crescimento de 32,4 p. p. de prefeitos com Ensino Superior (aumentando de 38\% para 50,3\%) e entre as prefeitas o aumento é de 48,6 p. p. (de 48,1\% passa para $71,5 \%$ ).

Tabela 8 - Evolução no nível de escolaridade das candidatas nas eleições majoritárias municipais $(\mathrm{em} \%)$

\begin{tabular}{lcccccc}
\hline & 1996 & 2000 & 2004 & 2008 & 2012 & 2016 \\
\hline Até o Ensino Fundamental & 17,4 & 13,9 & 11,7 & 9,9 & 6,9 & 5,5 \\
Ensino Médio & 25,8 & 36,4 & 33,3 & 31,9 & 28,1 & 22,3 \\
Ensino Superior & 29,2 & 49,2 & 54,8 & 58,2 & 65,0 & 72,2 \\
Sem dados & 27,6 & 0,6 & 0,3 & 0 & 0 & 0 \\
N & 100 & 100 & 100 & 100 & 100 & 100 \\
& 1122 & $1152)$ & 1536 & $1789)$ & 2153 & 2195 \\
\hline
\end{tabular}

Fonte: Elaboração do autor com dados do Tribunal Superior Eleitoral (2020). 
Tabela 9 - Evolução no nível de escolaridade dos candidatos nas eleições majoritárias municipais $(\mathrm{em} \%)$

\begin{tabular}{lcccccc}
\hline & 1996 & 2000 & 2004 & 2008 & 2012 & 2016 \\
\hline Até o Ensino Fundamental & 27,2 & 30,5 & 26,7 & 23,9 & 19,2 & 17,6 \\
Ensino Médio & 19,1 & 29,0 & 31,7 & 33,5 & 34,3 & 33,2 \\
Ensino Superior & 26,5 & 39,4 & 41,1 & 42,6 & 46,6 & 49,2 \\
Sem dados & 27,3 & 1,0 & 0,5 & 0 & 0 & 0 \\
$\mathrm{~N}$ & 100 & 100 & 100 & 100 & 100 & 100 \\
\hline
\end{tabular}

Fonte: Elaboração do autor com dados do Tribunal Superior Eleitoral (2020).

Tabela 10 - Evolução no nível de escolaridade das prefeitas (em \%)

\begin{tabular}{lcccccc}
\hline & 1996 & 2000 & 2004 & 2008 & 2012 & 2016 \\
\hline Até o Ensino Fundamental & 16,6 & 16,5 & 10,5 & 10,1 & 7,9 & 4,2 \\
Ensino Médio & 31,8 & 34,8 & 35,0 & 29,3 & 25,1 & 24,3 \\
Ensino Superior & 30,3 & 48,1 & 54,2 & 60,6 & 67,0 & 71,5 \\
Sem dados & 21,3 & 0,6 & 0,3 & 0 & 0 & 0 \\
N & 100 & 100 & 100 & 100 & 100 & 100 \\
& 277 & 322 & 408 & 536 & 673 & 650 \\
\hline
\end{tabular}

Fonte: Elaboração do autor com dados do Tribunal Superior Eleitoral (2020).

Tabela 11 - Evolução no nível de escolaridade dos prefeitos (em \%)

\begin{tabular}{lcccccc}
\hline & 1996 & 2000 & 2004 & 2008 & 2012 & 2016 \\
\hline Até o Ensino Fundamental & 28,2 & 31,2 & 26,3 & 23,1 & 18,4 & 17,7 \\
Ensino Médio & 19,2 & 30,0 & 33,1 & 34,1 & 34,6 & 32,0 \\
Ensino Superior & 27,9 & 38,0 & 40,2 & 42,8 & 47,1 & 50,3 \\
Sem dados & 24,8 & 0,9 & 0,3 & 0 & 0 & 0 \\
$\mathrm{~N}$ & 100 & 100 & 100 & 100 & 100 & 100 \\
\hline
\end{tabular}

Fonte: Elaboração do autor com dados do Tribunal Superior Eleitoral (2020).

Nota-se ainda que é grande a diferença entre homens e mulheres com Ensino Superior, tendo as mulheres maior nível de escolaridade que os homens e permanecendo essa diferença constante ao longo do tempo. A diferença entre os candidatos que, em 2000, era de 9,8 p. p., passou para 23 p. p., em 2016. Já entre as prefeitas e prefeitos, a diferença que era de 10,1 p. p., 
aumentou para 21,2 p. p. na eleição de 2016, reforçando ainda mais a tese de que a alta escolaridade é um importante fator para o acesso das mulheres aos executivos municipais.

A última variável a ser analisada neste estudo é o perfil ideológico dos candidatos nas eleições majoritárias municipais e dos prefeitos. Cabe destacar que os partidos de direita são os que mais possuem filiados no Brasil. Em 2002, tinham 45,9\% dos filiados (ÁLVARES, 2008, p. 907); em 2016, segundo o TSE, tais partidos passaram a ter 43\% do total de filiados; os partidos do centro possuíam 25,3\% e os de esquerda 31,7\%. Os partidos de direita também controlaram a Câmara dos Deputados nas legislaturas de 1998 a 2014. Em média, pouco mais de 40\% dos deputados federais eram filiados a esses partidos, enquanto a esquerda foi sempre a terceira força política, exceto em 2010, quando conquistou 166 cadeiras das 513 disponíveis, ultrapassando, pela primeira e única vez, o centro que tinha 163 eleitos (CODATO; BERLATTO; BOLOGNESI, 2018, p. 877).

Já os governos estaduais, que são grandes cabos eleitorais dos prefeitos, nos últimos anos foram administrados por governadores filiados a partidos mais ao centro, principalmente, pelo PMDB e PSDB. No entanto, desde a eleição de 2002, ano da vitória do Partido dos Trabalhadores para a Presidência da República, é grande o percentual dos estados brasileiros comandados por governadores de partidos de esquerda, principalmente, por governadores filiados ao PT e ao PSB (Tabela 12).

Tabela 12 - Evolução no espectro ideológico dos governadores estaduais (em \%)

\begin{tabular}{lcccccc}
\hline & 1994 & 1998 & 2002 & 2006 & 2010 & 2014 \\
\hline Esquerda & 22,2 & 22,2 & 37,0 & 44,4 & 44,4 & 44,4 \\
Centro & 55,6 & 48,1 & 44,4 & 48,1 & 48,1 & 51,9 \\
\multirow{2}{*}{ Direita } & 22,2 & 29,6 & 18,5 & 7,4 & 7,4 & 3,7 \\
$\mathrm{~N}$ & 100 & 100 & 100 & 100 & 100 & 100 \\
& 27 & 27 & 27 & 27 & 27 & 27 \\
\hline
\end{tabular}

Fonte: Elaboração do autor com dados do Tribunal Superior Eleitoral (2020).

Nas análises das eleições majoritárias municipais, os partidos de direita e de centro foram os que mais lançaram candidatos nas últimas seis eleições, pertencendo, também, a partidos desses dois espectros, a grande maioria dos prefeitos que foram eleitos (Gráfico 4). 
Gráfico 4 - Espectro ideológico dos candidatos nas eleições majoritárias municipais e dos prefeitos (1996-2016)

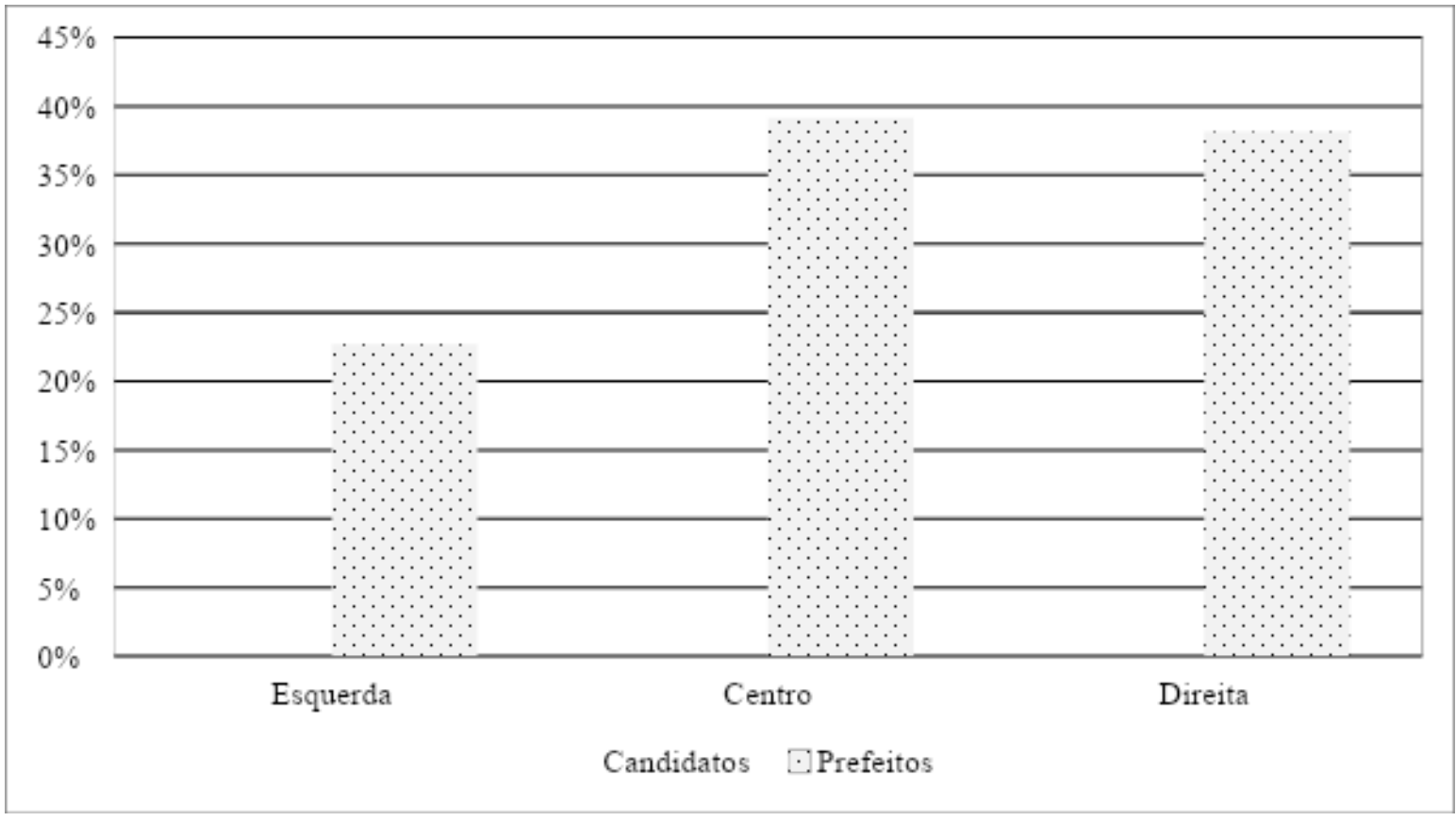

Fonte: Elaboração do autor com dados do Tribunal Superior Eleitoral (2020).

$\mathrm{Na}$ evolução do tempo, percebe-se que os partidos com ideologias voltadas para direita sempre lançaram a maior quantidade de candidatos nas disputas eleitorais para prefeitos até a eleição de 2008, tornando-se o espectro político que mais lançou candidatos em 2016, mas com expressiva redução no número de candidatos lançados por tal eixo ideológico entre 1996 e 2016, saindo de 43,7\% para 34,5\%, uma diminuição de 21 p. p.. Consequentemente, até a eleição de 2008, a maioria dos prefeitos eram filiados a partidos mais de direita e, devido à diminuição no número de candidatos, houve uma queda no número de prefeitos vinculados a esses partidos entre 1996 a 2016 (Gráficos 5 e 6). A queda no número de candidatos e prefeitos nos partidos de direita se deu, em grande parte, em decorrência da diminuição do poder desses partidos, após o ano de 2003, no controle do governo federal e nos governos estaduais. Somente o PFL/DEM, um dos principais partidos de direita no Brasil, nos últimos 20 anos, teve uma redução em quase 70 p. p. no número de seus candidatos disputando as eleições majoritárias municipais e mais de 72 p. p. de prefeitos eleitos por sua legenda.

Houve também uma redução no número de candidatos e de prefeitos nos partidos denominados de centro no espectro político entre 1996 e 2004 e nas últimas 3 eleições (2008, 2012 e 2016). Os partidos desse eixo conseguiram aumentar a quantidade de candidatos e, consequentemente, aumentaram o número de prefeitos filiados aos seus partidos. Nota-se ainda que, apesar dos partidos do centro não serem os responsáveis por lançarem o maior número de 
candidatos, nas últimas duas eleições, são os partidos desse eixo que mais elegeram prefeitos em 2012 e 2016.

Já entre os partidos de esquerda, há um grande crescimento, tanto no número de candidatos, quanto no número de prefeitos filiados a esses partidos. Entre 1996 e 2016, há um crescimento de mais de 42 p. p. no número de candidatos e, nesse mesmo período, ocorreu um aumento de mais de 73 p. p. entre os prefeitos eleitos com filiação aos partidos de esquerda. Esses aumentos se explicam, sobretudo, com a chegada do Partido dos Trabalhadores no Governo Federal, na eleição de 2002, e sua base de apoio ser com partidos de esquerda, comandando a esfera federal por quase 14 anos. Só no PT, entre 1996 e 2012, houve um crescimento de 65 p. p. no número de candidatos e um aumento de 447 p. p. no número de prefeitos eleitos. Mas percebe-se que, na eleição de 2016, houve uma redução tanto no número de candidatos, quanto no número de prefeitos nos partidos do bloco de esquerda. Esse fato ocorreu provavelmente devido ao grande desgaste e rejeição que o Partido dos Trabalhadores enfrentou com a forte crise política e econômica que o Brasil atravessou entre 2014/2016, ocasionando o Impeachment da presidenta Dilma Rousseff (PT), no dia 31 de agosto de 2016, véspera do primeiro turno da eleição de 2016, ocorrida em 02 de outubro de 2016. Houve, ainda, em 2014, a morte de Eduardo Campos, ex-governador de Pernambuco e ex-presidente do PSB, possivelmente, ocasionando a diminuição de candidatos deste partido nas últimas eleições em análise.

Infere-se, a partir desses dados, que, tanto o partido político que ocupa a esfera nacional de poder como as conjunturas partidárias nos governos estaduais, influenciaram nos processos de maior ou menor número de candidatos nas disputas e nos resultados eleitorais nos municípios. Percebe-se que, com a saída de Fernando Henrique Cardoso (PSDB) da Presidência da República no ano de 2002, e sua coalizão de direita (PSDB, PFL e PTB), no primeiro mandato, e de centro-direita (PSDB, PFL, PPB/PP, PTB e PSD), no segundo mandato, e a diminuição de governadores estaduais desses partidos, sobretudo do PFL/DEM, diminuíram tanto o número de candidatos como o de prefeitos eleitos por partidos de direita. Com a chegada de Luiz Inácio Lula da Silva (PT) ao governo federal em 2003, por meio de um partido de esquerda e o aumento no número de governadores desse espectro político nos estados, houve um aumento no número de candidatos nas eleições majoritárias municipais e de prefeitos por partidos mais de esquerda. 
Gráfico 5 - Evolução no espectro ideológico dos candidatos nas eleições majoritárias municipais

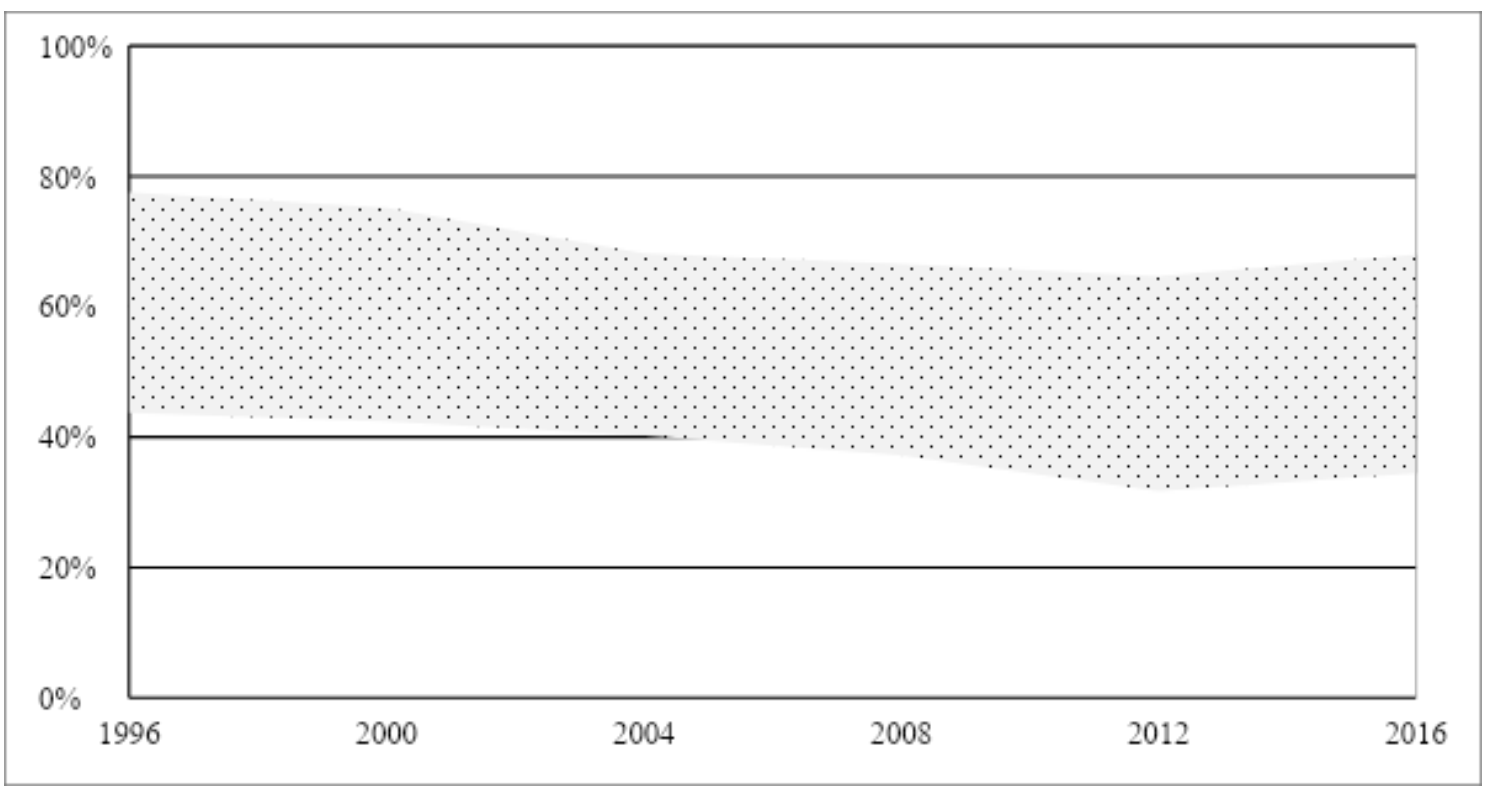

Fonte: Elaboração do autor com dados do Tribunal Superior Eleitoral (2020).

Gráfico 6 - Evolução no espectro ideológico dos prefeitos brasileiros

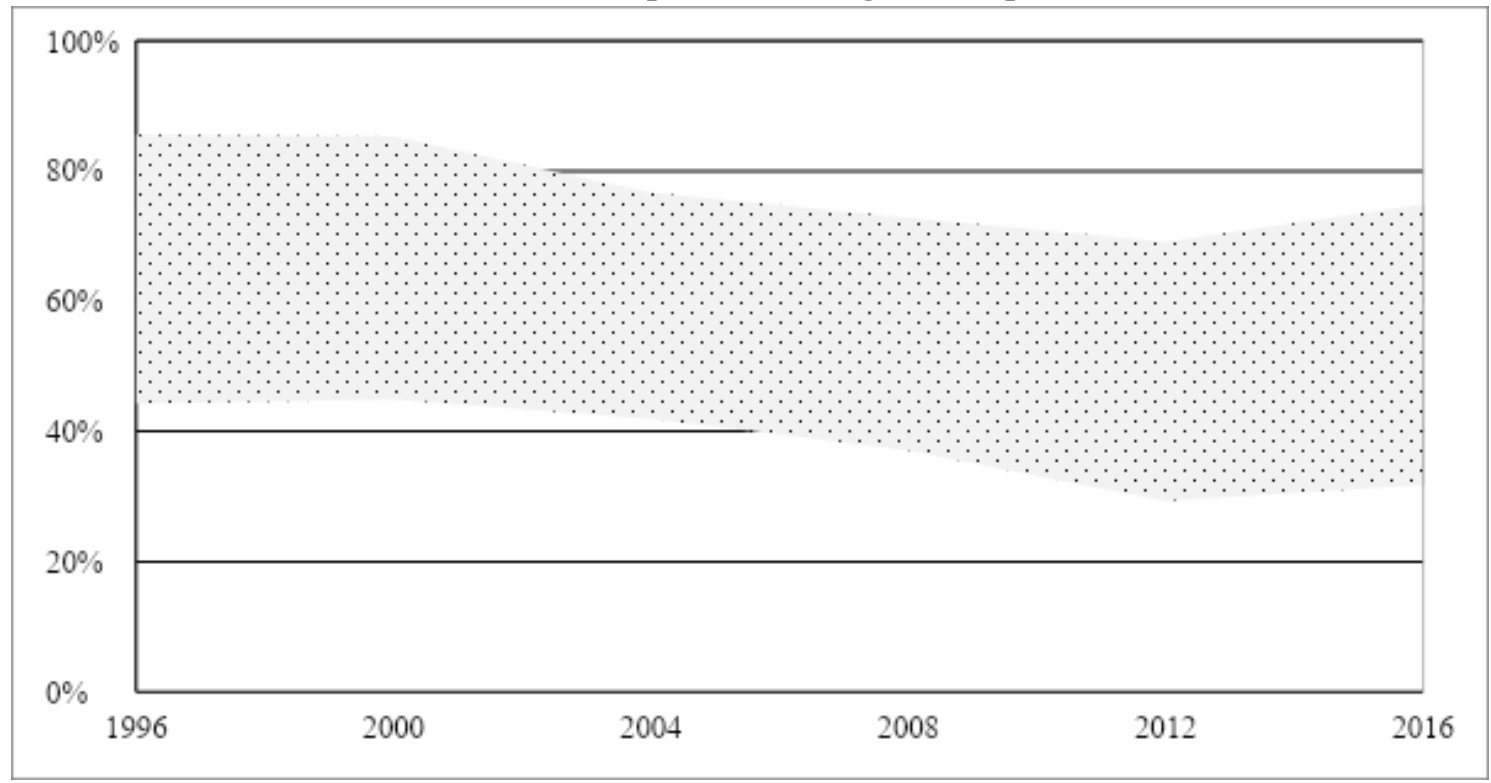

Fonte: Elaboração do autor com dados do Tribunal Superior Eleitoral (2020).

Por fim, ao analisar a evolução do sexo dos candidatos e dos prefeitos nos blocos ideológicos, nota-se a predileção das mulheres e dos homens por partidos mais conservadores para disputar pleitos majoritários municipais até 2008, apesar de a literatura apontar que os partidos de esquerda foram os primeiros a oferecerem suporte para inserção das mulheres no cenário político (MIGUEL; QUEIROZ, 2006). Entre as mulheres, a maior parte das candidatas 
sempre foram de partidos de direita ou de centro. Já entre os homens, apenas na eleição de 2012 houve mais candidatos por partidos de esquerda que por partidos de centro ou de direita. Entre os eleitos, de 1996 a 2008, a maior parte das prefeitas e dos prefeitos pertenciam a partidos de centro; após a eleição de 2012, a maioria deles encontravam-se filiados a partidos de direita (Gráficos 7 e 8).

Gráfico 7 - Evolução no perfil ideológico das candidatas nas eleições majoritárias municipais e das prefeitas
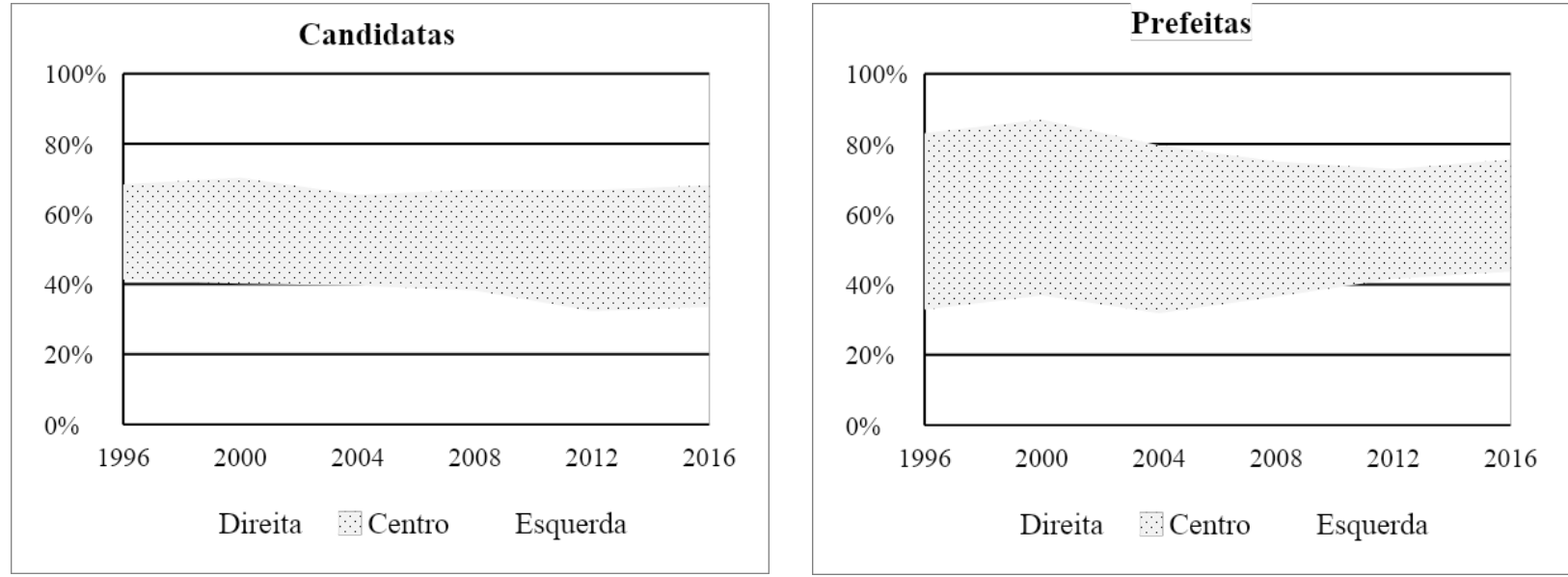

Fonte: Elaboração do autor com dados do Tribunal Superior Eleitoral (2020).

Gráfico 8 - Evolução no perfil ideológico dos candidatos nas eleições majoritárias municipais e dos prefeitos
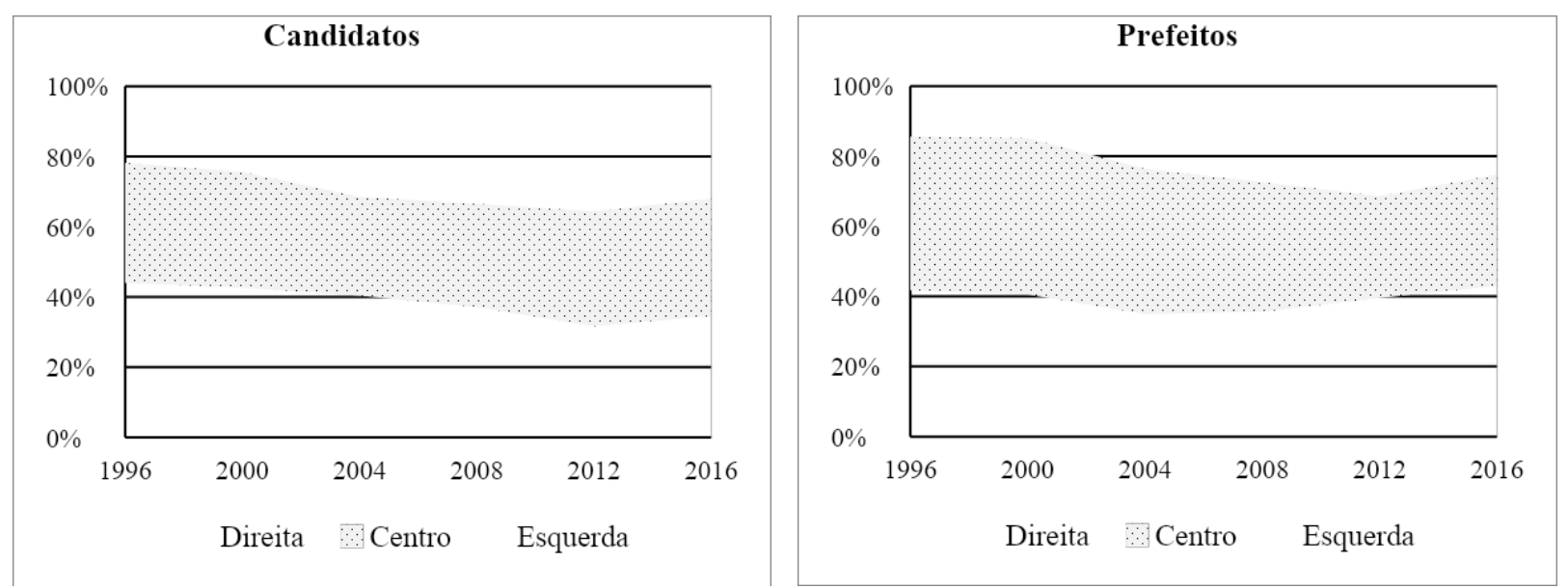

Fonte: Elaboração do autor com dados do Tribunal Superior Eleitoral (2020). 


\section{CONSIDERAÇÕES FINAIS}

Neste artigo, foi exposto o perfil social e ideológico dos candidatos e dos prefeitos brasileiros dos últimos 20 anos. Pôde-se concluir, a partir da análise, que existe uma grande diferença entre mulheres e homens participando das eleições e um número bem menor delas sendo eleitas para ocuparem o cargo de prefeita. Entretanto, nas últimas décadas, houve uma elevação da participação política das mulheres nas disputas para o cargo de prefeita e, consequentemente, um aumento no número de prefeitas. Há uma tendência no aumento da média das idades dos candidatos nas eleições majoritárias municipais e dos prefeitos, tanto das mulheres como dos homens, apontando para um "envelhecimento" dos administradores dos executivos municipais. Enquanto na eleição de 1996, se elegia candidatos com a menor média de idades, em 2016, ocorreu o pleito que elegeu prefeitas e prefeitos com uma maior média de idade no período.

O nível de escolaridade dos candidatos e dos prefeitos é alto: mais de $42 \%$ dos candidatos e dos prefeitos possuíam o Ensino Superior como grau de instrução. Na evolução do tempo há, ainda, uma ampliação desse nível de escolaridade, chegando a eleição de 2016 ter mais da metade dos candidatos e dos prefeitos eleitos com uma graduação. Foram os partidos de direita e de centro os que mais lançaram candidatos nas últimas seis eleições, pertencendo também a partidos desses dois espectros a grande maioria dos prefeitos que foram eleitos. Porém, com a chegada do PT à Presidência da República, em 2003, houve uma redução no número de candidatos e de prefeitos filiados a partidos mais de direita no espectro político e um crescimento considerável tanto no número de candidatos quanto no número de prefeitos filiados aos partidos de esquerda.

Nessa perspectiva, os resultados mostram disparidades no perfil dos candidatos e dos prefeitos municipais na comparação com o perfil da população brasileira, mostrando-se uma classe mais masculina, diferenciada e "superior" como toda classe política. Cabe destacar que para uma melhor investigação no perfil dos candidatos e dos prefeitos, não configuraram análises sobre a profissão/ocupação e a declaração de bens que estes informaram à Justiça Eleitoral no ato do registro das candidaturas, além da presença de outros capitais muito presentes na classe política brasileira a serem verificados, como o capital familiar, religioso e cultural (midiático).

\section{REFERÊNCIAS}

ALCÁNTARA, M. (2016). A profissionalização da política / Manuel Alcántara; Tradução de Renata Oliveira Rufino. Curitiba: CPOP-PPGCP/UFPR. 
ALMEIDA, R. M. de. (2019). Curso de Direito Eleitoral / Roberto Moreira de Almeida - 13a ed. rev. ampl. e atual. Salvador: JusPODIvm.

ÁLVARES, M. L. M. (2008). Mulheres brasileiras em tempo de competição eleitoral: seleção de candidaturas e degraus de acesso aos cargos parlamentares. DADOS - Revista de Ciências Sociais, Rio de Janeiro, vol. 51, $\mathrm{n}^{\circ}$ 4, p. 895-939.

ALVES, J. E. D. (1998). As mulheres no poder. Estado de Minas, Belo Horizonte, p. 7, 29 jul.

AlveS, J. E. D., CAVENAGHI, S. M., ALCÂNTARA, A. P. de. (2007). Participação das mulheres nas eleições de 2004: avaliação da política de cotas no Brasil. Gênero, Niterói, vol. 7, n 2, p. 195-215, 1. sem.

ARAÚJO, P. M. (2011). Recrutamento parlamentar para o Senado e o perfil dos senadores brasileiros, 1989-2006. Política Hoje, vol. 20, n 2, p. 550-580.

BOHN, S. (2008). Mulheres e qualidade das candidaturas nas eleições para o Senado. In: LEMOS, L. B. (Org.). O Senado Federal brasileiro no pós-Constituinte. Brasília: Unilegis.

BOHN, S. (2009). Mulheres brasileiras na disputa do legislativo municipal. Perspectivas, São Paulo, vol. 35, p. 63-89, jan./jun.

BRAGA, M. do S., VEIGA, L. F., MIRÍADE, A. (2009). Recrutamento e Perfil dos candidatos e dos eleitos à Câmara dos deputados nas eleições de 2006. RBCS, vol. 24, nº 70, p. 123-142, junho.

CLARK, J. (1994). "Getting there: women in political office". In: GITHENS, M., NORRIS, P., LOVENDUSKI, J. (Orgs.). Differentroles, differentvoices. New York: Harper-Collins.

CODATO, A., BERLATTO, F., BOLOGNESI, B. (2018); Tipologia dos políticos de direita no Brasil: uma classificação empírica. Análise Social, liii (4. $\left.{ }^{\circ}\right), \mathrm{n}^{\circ}$ 229, p. 870-897.

CODATO, A., CERVI, E., PERISSINOTTO; R. (2013). Quem se elege prefeito no Brasil? Condicionantes do sucesso eleitoral em 2012. Cadernos Adenauer XIV, Rio de Janeiro, vol. 14, $\mathrm{n}^{\circ}$ 2, p. 61-84.

CONWAY, M. M., STEUERNAGEL, G. A., AHERN, D. W. (1997). Women and political participation. Washington: Congressional Quarterly Press.

COSTA, L. D. (2010). Os representantes dos estados no Congresso: composição social e carreira politica dos Senadores brasileiros. Campinas. Dissertação (Mestrado em Ciência Política). Universidade Estadual de Campinas - Unicamp.

COSTA, L. D., CODATO, A. N. (2013). Profissionalização ou popularização da classe política brasileira? Um perfil dos senadores da república. In: SANTOS, A. M. dos (Org.). Os eleitos: representação e carreiras políticas em democracias. Porto Alegre: Ed. UFRGS.

DARCY, R., WELCH, S., CLARK, J. (1994). Women, elections, and representation, $2^{a}$ ed. Lincoln: University of Nebraska Press.

DUERST-LAHTI, G. (1998). The bottleneck, women as candidates. In: THOMAS, S. WILCOX, C. (Orgs.). Women and elective office. New York: Oxford University Press. 
FRASER, N., HONNETH, A. (2003). Redistribution or recognition? A political-philosophical exchange. London: Verso.

FREIRE, A. (1998). Lógicas de recrutamento parlamentar: os deputados portugueses, 1975-1999. Sociologia - Problemas e Práticas, no 28, p. 115-147.

LEMOS, L. B. de S., RANINCHESKI, S. (2003). Carreras políticas en el Senado brasileño: Un estudio de las composiciones del Pleno y de la Comisión de Constitución, Justicia y Ciudadanía en la década de 90. Lateinamerika Analysen. Hamburg.

LODOLA, G. (2017). Reclutamiento político subnacional. Composición social y carreras políticas de los gobernadores en Argentina. Colombia Internacional, n 91, p. 85-116.

MARENCO, A., SERNA, M. (2007). Por que as carreiras políticas na esquerda e na direita não são iguais? Recrutamento legislativo em Brasil, Chile e Uruguai. Revista Brasileira de Ciências Sociais, vol. $22, \mathrm{n}^{\circ} 64$.

MASSIA, L. P. (2013). A Profissionalização política do poder executivo estadual: uma análise do perfil social e da carreira dos governadores brasileiros (1994-2010). Pelotas. Dissertação (Mestrado em Ciência Política). Universidade Federal de Pelotas, Instituto de Filosofia, Sociologia e Política.

MATLAND, R. E. (2005). Enhancing Women's Political: Legislative Recruitmentand Electoral Systems. In: BALLINGTON, J., KARAM, A. (Eds.). Women in Parliament: Beyond Numbers (ed. revista). Stockholm, IDEA.

MIGUEL, L. F. (2004). Participação eleitoral e gênero no Brasil: as cotas para mulheres e seu impacto. Trabalho apresentado no II Congresso da Associação Latino-Americana de Ciência Política (ALACIP), Cidade do México, 29 de setembro a 2 de outubro.

MIGUEL, L. F., MARQUES, D. MACHADO, C. (2015). Capital Familiar e Carreira Política no Brasil: Gênero, Partido e Região nas Trajetórias para a Câmara dos Deputados. Dados - Revista de Ciências Sociais, vol. 58, $\mathrm{n}^{\circ}$ 3, p. 721-747, julho-setembro.

MIGUEL, L. F., QUEIROZ, C. M. (2006). Diferenças Regionais e o êxito relativo de mulheres em eleições municipais no Brasil. Revista Estudos Feministas, vol. 14, p. 363-385.

NEIVA, P., IZUMI, M. Os (2012). "Doutores" da federação: formação acadêmica dos senadores brasileiros e variáveis associadas. Revista Sociologia e Política, vol. 20, n 41, p. 171-192.

NORRIS, P., LOVENDUSKI, J. (1995). Political recruitment: gender: race and class in the British Parliament. Cambridge, Cambridge University Press.

PEIXOTO, V. de M., SILVA, G. T. (2017). Mulheres nas Eleições Proporcionais Municipais de 2016. Teoria \& Pesquisa, vol. 26, p. 39-59.

PERISSINOTTO, R. M., BOLOGNESI, B. (2009). O recrutamento político no PT e no PFL paranaenses nas eleições de 2006: sugestões de pesquisa. Mediações, vol. 14, n 1, p. 143-169, Jan/Jun. 
PERISSINOTTO, R. M., BOLOGNESI, B. (2010). Electoral Success and Political Institutionalization in the Federal Deputy Elections in Brazil (1998, 2002 and 2006). Brazilian Political Science Review, vol. 4, n 1, p. 10-32.

PERISSINOTTOO, R. M., MIRÍADE, A. (2009). Caminhos para o parlamento: candidatos e eleitos nas eleições para deputado federal em 2006. Dados, vol. 52, nº 2, p. 301-333.

PINTO, C. R. J., SILVEIRA, A. (2018). Mulheres com carreira política longevas no legislativo brasileiro (1950-2014). Opinião Pública, Campinas, vol. 24, nº 1, p. 178-208, jan.-abr.

PRATTI. L. P. (2013). Perfil social, recrutamento e trajetórias politicas: uma análise dos representantes do Legislativo Estadual capixaba, 1986-2010. Vitória. Dissertação (Mestrado em Ciências Sociais). Universidade Federal do Espírito Santo, Centro de Ciências Humanas e Naturais.

RODRIGUES, L. M. (2006). Mudanças na classe politica brasileira. São Paulo: Publifolha.

RODRIGUES, L. M. (2002). Partidos políticos, ideologia e composição social. RBCS, vol. 17, nº 48, fevereiro.

SANTANA, L. (2008). Perfil, Trajetórias e ambição política dos legisladores na construção de suas carreiras: Argentina, Brasil, Chile e Uruguai. Teoria e Sociedade, vol. 2, n 16, p. 130-155, jun.dez.

SANTOS, F. (2010). Câmara dos Deputados e a estrutura de oportunidades políticas no Brasil: alguns apontamentos acerca das eleições de 2010. Cadernos Aslegis, nº 40, p. 109-126.

SIGAL, S. (2002). Intelectuales y poder en Argentina. La década del sesenta. Buenos Aires: Siglo XXI.

SILVA JÚNIOR, J. A. da, FIGUEIREDO FILHO, D. B. (2012). Marolas ou tsunamis? O impacto das ondas de renovação sobre a profissionalização dos deputados federais (1999-2003). Revista de Sociologia e Política, vol. 20, n 42, p. 199-212.

SILVA, B. F., SILVA, B. T. (2015). Perfil social e ideologia partidária: uma análise do recrutamento dos candidatos a vereador em Curitiba (2012). MEDLACOOES, Londrina, vol. 20, nº 2, p. 340-365, Jul./Dez.

SILVA, R. S. da. (2010). Senado: casa de senhores? Os perfis de carreira dos senadores eleitos entre 1990-2006. Porto Alegre. Dissertação (Mestrado em Ciência Política). Universidade Federal do Rio Grande do Sul.

SILVA, V. G. (2016). Mudanças no perfil dos deputados federais nos três principais partidos políticos do Brasil (PT, PMDB E PSDB) em 24 anos de democracia. Campos dos Goytacazes, RJ. Trabalho de Conclusão de Curso (Bacharelado em Administração Pública). Universidade Estadual do Norte Fluminense Darcy Ribeiro, Laboratório de Gestão e Políticas Públicas.

SOULE. J. W. (1969). Future Political Ambitions and the Behavior of Incumbent State Legislators. Legislative, Midwest Journal of PoliticalScience, vol. 13, n 3, p. 439-454.

THOMAS, S. (1998). Introduction: women and elective office: past, present, and future. In: THOMAS, S., WILCOX, C. (Orgs.). Women and elective office. New York: Oxford University Press. 